\title{
A Visualization Method of Quantifying Carbon Combustion Energy in the Sintering Packed Bed
}

\author{
Chengfeng SUN, ${ }^{1)}$ Yizhang YANG ${ }^{1)}$ Yang XU, ${ }^{1)}$ Zhehan LIAO, ${ }^{1)}$ Yuandong PEI, ${ }^{2)} \mathrm{Qi} Z \mathrm{ZHOU},{ }^{3)}$ Xuewei $\mathrm{LV}^{1,4)}$ and \\ Jian $X U^{1,4) *}$ \\ 1) College of Materials Science and Engineering, Chongqing University, Chongqing, 400044 China. \\ 2) Zenith Steel Group Company Limited, Changzhou, 213001 China. \\ 3) Baogang Zhanjiang Iron and Steel Company Limited, Zhanjiang, 524072 China. \\ 4) Chongqing Key Laboratory of Vanadium-Titanium Metallurgy and Advanced Materials, Chongqing University, Chongqing, \\ 400044 China.
}

(Received on November 15, 2020; accepted on March 1, 2021; J-STAGE Advance published date: April $21,2021)$

\begin{abstract}
Carbon combustion provides energy to reach essential temperatures in the sintering packed bed. A visual and quantitative evaluation on the energy input distribution inside the bed is urgently demanded to learn energy-saving potential of sintering process and subsequently to suppress greenhouse gas emission. Herein, after a two-dimensional simplified model of sintering packed bed is established and validated against the temperature measurements on the sintering pot experiment, this work highlights a meshbased visualization method of quantifying carbon combustion energy in the packed bed. To be more specific, local transient temperature distributions in all meshed grids are first extracted from numerical simulation results. Then each grid is colorized according to the specific criteria on five pre-defined energy input (El) states. As a result, the effects of carbon segregation and cross-sectional shape on the energy efficiency of sintering packed bed are quantitatively compared and optimized. These two case studies not only demonstrate the principle, process, and application of the proposed visualization method, but also stimulate its future potential in various areas.
\end{abstract}

KEY WORDS: visualization method; carbon combustion energy; sintering packed bed; carbon segregation; cross-sectional shape.

\section{Introduction}

The packed bed reactor have wide applications in the different chemical processes, such as the absorption, ${ }^{1)}$ the distillation, ${ }^{2)}$ the stripping, ${ }^{3)}$ the separation, ${ }^{4)}$ the solid fuel combustion, ${ }^{5)}$ and the iron ore sintering process. ${ }^{6,7)}$ The carbon combustion in the packed bed supports desired temperatures for the chemical reactions in the sintering process, ${ }^{8)}$ which significantly affects yield and quality of products. ${ }^{9,10)}$ Therefore, lots of efforts on temperature profile optimization have been made by controlling carbon grain size distribution, ${ }^{11,12)}$ blowing natural gas, ${ }^{13,14)}$ and so on.

On the other hand, the duration above a specific temperature also makes an important influence on the reaction kinetics in the packed bed, ${ }^{15,16)}$ which has been widely investigated by experimental ${ }^{17-23)}$ and numerical ${ }^{24-29)}$ studies over the past decades. Machida et al. ${ }^{30)}$ established a relationship between products' strength and the duration

\footnotetext{
* Corresponding author: E-mail: jxu@cqu.edu.cn
}

above melting temperature, and the total heat available in the critical melt formation stage ${ }^{9)}$ was further determined. ${ }^{31)}$ Meanwhile, either one-dimensional ${ }^{32,33)}$ or two-dimensional model $^{10)}$ was solved to predict the temperature profiles against the time, and a residence time of approximately 10 mins at 1 473-1 $673 \mathrm{~K}$ was expected to be reasonable for liquid phase generation in the packed bed. ${ }^{34)}$

Although lots of work has successfully established the relations between the temperature profile and the sintering time, few works focus on proposing a visualization method to quantitatively evaluate carbon combustion energy in the packed bed. Therefore, this work first predicts and validates the transient temperature versus the time in a carbon combustion packed bed through a two-dimensional simplified model. Then five energy input (EI) states are defined based on the specific criteria, and the cross section of the carbon combustion packed bed is colorized and evaluated based on the meshed grids. Furthermore, two case studies, namely the effects of the carbon segregation and the crosssectional shape on the energy efficiency in the packed bed, 
are demonstrated to understand the definition, process and application of the proposed visualization method, as well as to stimulate its future prospects in other fields.

\section{Experimental and Numerical Methods}

The laboratory-scale sintering pot experiment is used to simulate the carbon combustion in a packed bed, and its schematic diagram is shown in the Fig. 1. The pot has an inner diameter of $40 \mathrm{~cm}$ and a height of $63 \mathrm{~cm}$. Three thermocouples are respectively installed at $\mathrm{H}=15,33$, and 48 $\mathrm{cm}$ measured from the bottom, to record the transient temperatures in the whole process. After approximately $60 \mathrm{~kg}$ raw materials including $3.2 \mathrm{wt} \%$ carbon are charged into the pot, the combustion starts when the carbon is ignited by the liquefied gas from the top at a negative pressure of $15 \mathrm{kPa}$.

Meanwhile, a 1:1 scale two-dimensional simplified EulerEuler model for the numerical simulation is established in terms of mass, momentum, energy and specie conservation equations of gas and solid phases respectively in Eqs. (1)-(6).

Gas phase mass conservation:

$$
\frac{\partial}{\partial t}\left(\varepsilon \cdot \rho_{g}\right)+\frac{\partial}{\partial y}\left(\varepsilon \cdot \rho_{g} \cdot u_{g}\right)=\sum_{k=1}^{n} \dot{m_{k}}
$$

Gas phase momentum conservation:

$$
\frac{\partial}{\partial t}\left(\varepsilon \cdot \rho_{g} \cdot u_{g}\right)+\frac{\partial}{\partial y}\left(\varepsilon \cdot \rho_{g} \cdot u_{g} \cdot u_{g}\right)=-\varepsilon \cdot \frac{\partial P}{\partial y}-F_{v}
$$

Gas phase energy conservation:

$$
\begin{aligned}
\frac{\partial}{\partial t}\left(\varepsilon \cdot \rho_{g} \cdot h_{g}\right)+\frac{\partial}{\partial y}\left(\varepsilon \cdot \rho_{g} \cdot u_{g} \cdot h_{g}\right) & =h_{\text {conv }} \cdot A_{s} \cdot\left(T_{g}-T_{s}\right) \\
& +\sum_{k=1}^{n} \dot{q_{g, k}}
\end{aligned}
$$
$\mathrm{H}_{2} \mathrm{O}$ ):

$$
\frac{\partial}{\partial t}\left(\varepsilon \cdot \rho_{g} \cdot Y_{i}\right)+\frac{\partial}{\partial y}\left(\varepsilon \cdot \rho_{g} \cdot u_{g} \cdot Y_{i}\right)=\sum_{k=1}^{n} \sum_{i} m_{i, k}
$$

Solid phase mass conservation:

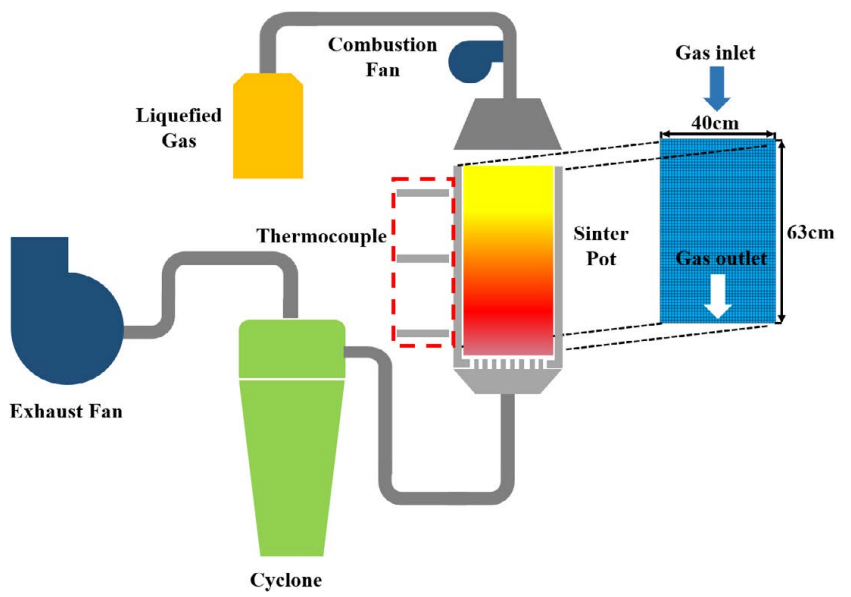

Fig. 1. The schematic diagram of the laboratory-scale sintering pot experiment and the corresponding dimensions and boundary conditions for the numerical simulation. (Online version in color.)

$$
\frac{\partial \rho_{s}}{\partial t}=-\sum_{k=1}^{n} \dot{m_{k}}
$$

Solid phase energy conservation:

$\frac{\partial}{\partial t}\left(\rho_{s} \cdot h_{s}\right)=\frac{\partial}{\partial y}\left(\frac{k_{s, e f f}}{C_{p_{s}}} \cdot \frac{\partial h_{s}}{\partial y}\right)+h_{c o n v} \cdot A_{s} \cdot\left(T_{g}-T_{s}\right)+\sum_{k=1}^{n} q_{s, k}$

Besides, the carbon combustion reaction in the present model has two intermediate steps: ${ }^{35)}$ the carbon is first oxidized to $\mathrm{CO}$ by $\mathrm{O}_{2}$, and then it is further oxidized to $\mathrm{CO}_{2}$. The corresponding reaction rates are determined by Eqs. $(7)^{36)}$ and $(8),{ }^{37)}$ respectively.

$$
\begin{gathered}
R_{\text {carbon }}=\frac{2 A_{c} W_{c} C_{O_{2}}}{\frac{1}{\xi k_{c}}+\frac{1}{k_{\text {film }}}+\frac{1}{k_{\text {coating }}}} \ldots \ldots \ldots \ldots \ldots \ldots \ldots \ldots \ldots . . . . . . . \\
R_{c o}=3.25 \cdot 10^{7} C_{c o} C_{O_{2}}{ }^{1 / 2} C_{h_{2} O}{ }^{1 / 2} \exp \left(-\frac{15089}{T_{g}}\right) \ldots . .
\end{gathered}
$$

where, $k_{c}$ is the rate constant, $k_{f i m}$ is the film mass transfer coefficient, $k_{\text {coating }}$ is the mass transfer coefficient through the coating solids and the developing ash layer. Besides, the particle radius $r_{0}$ is initialized as $0.002 \mathrm{~m}$, while the carbon radius $r_{i, \text { carbon }}$ decreases as the combustion proceeds, which is described by Eq. (9).

$$
r_{i, \text { carbon }}=r_{0}\left(1-\frac{\left(Y_{0, \text { carbon }}-Y_{i, \text { carbon }}\right)}{Y_{0, \text { carbon }}}\right)^{\frac{1}{3}}
$$

where, $Y_{0, \text { carbon }}$ is initial carbon mass fraction, $Y_{i, \text { carbon }}$ is the transient carbon mass fraction.

For boundary conditions, the top surface is the gas velocity inlet while the bottom is the gas pressure outlet, both side-wall are stationary and adiabatic. The bed voidage is supposed to have a linear relationship with the temperature by fitting the data from Wang et al.' work. ${ }^{38)}$ The pre-test results of the established model reveals that the transient carbon particle radius and bed voidage make limited effect on the carbon combustion rate, while the prediction of the

Table 1. The parameters for the numerical simulation.

\begin{tabular}{cc}
\hline Parameters & Values \\
\hline Gas temperature at the inlet (ignition stage) $(\mathrm{K})$ & 1273 \\
Gas pressure at the outlet (ignition stage) $(\mathrm{kPa})$ & -15 \\
Ignition duration period(s) & 120 \\
Gas temperature at the inlet (combustion stage) $(\mathrm{K})$ & 300 \\
Gas pressure at the outlet (combustion stage) $(\mathrm{kPa})$ & -10 \\
Initial solid temperature $(\mathrm{K})$ & 300 \\
Solid density $\left(\mathrm{kg} / \mathrm{m}^{3}\right)$ & 2719 \\
Solid specific heat $\mathrm{J} /(\mathrm{kg} \cdot \mathrm{K})$ & 871 \\
Voidage in the packed bed $(-)$ & 0.35 \\
Particle radius $(\mathrm{m})$ & 0.002 \\
Time step (s) & 1 \\
Calculation time (s) & 3000
\end{tabular}


bed voidage distribution by directly solving conservation equations is challenging. Alternatively, the bed voidage is considered to be constant $(0.35)$ in the following analysis. The other specific parameters ${ }^{39-41)}$ for numerical simulation are listed in the Table $\mathbf{1 .}$

The simulated transient temperatures at $\mathrm{H}=15,33$, and $48 \mathrm{~cm}$ against the process time are compared with the experimental measurements in the Fig. 2(a). The differences in the maximum temperatures and the periods to reach the corresponding maximum temperatures between the measured and simulated results are less than $75 \mathrm{~K}$ and $24 \mathrm{~s}$, respectively. In addition, the measured sintering time and the times when the flame front (FF) reaching specific heights or the times when the temperature starts to rise, are compared with the simulated results in the Fig. 2(b). The difference in the sintering time between the experiment and simulation is less than 3 minutes, while the simulated times when the FF reaches individual heights is shorter than the measured counterparts. The discrepancies in the temperature profile and the corresponding FF distributions between the experimental and numerical results attribute to the following two reasons. First, the established model is simplified by neglecting other complex physical and chemical processes, such as the melting and solidification process, the migration process of water, the shrinkage process of bed height after combustion, and so on. Second, the sealing problems strengthen the heat loss in the lower part of sintering pot. Nevertheless, the consistent trends in temperature distributions with acceptable differences agree that this simplified model is capable of providing quantitative data to introduce the visualization method. Meanwhile, the snaps of the solid temperature profiles at $120 \mathrm{~s}, 1100 \mathrm{~s}$, and $2155 \mathrm{~s}$ are demonstrated in the Fig. 2(c). The solid temperature increases to $1273 \mathrm{~K}$ when the ignition finishes at $120 \mathrm{~s}$, and the thickness of the high temperature zone between 923 and 1621 $\mathrm{K}$ is approximately $3 \mathrm{~cm}$ in the vertical direction. At 1100 $\mathrm{s}$, the maximum solid temperature is increased by $458 \mathrm{~K}$ and the thickness of the aforementioned high temperature zone enlarges to $18 \mathrm{~cm}$. When the carbon combustion in the packed bed closes to the end, the maximum solid temperature and the thickness of the high temperature zone reach as great as $1621 \mathrm{~K}$ and $19 \mathrm{~cm}$, respectively. In short, the transient temperature profile versus the process time in the Fig. 2(d) provides quantitative information to evaluate the energy storage effect. ${ }^{42-44)}$

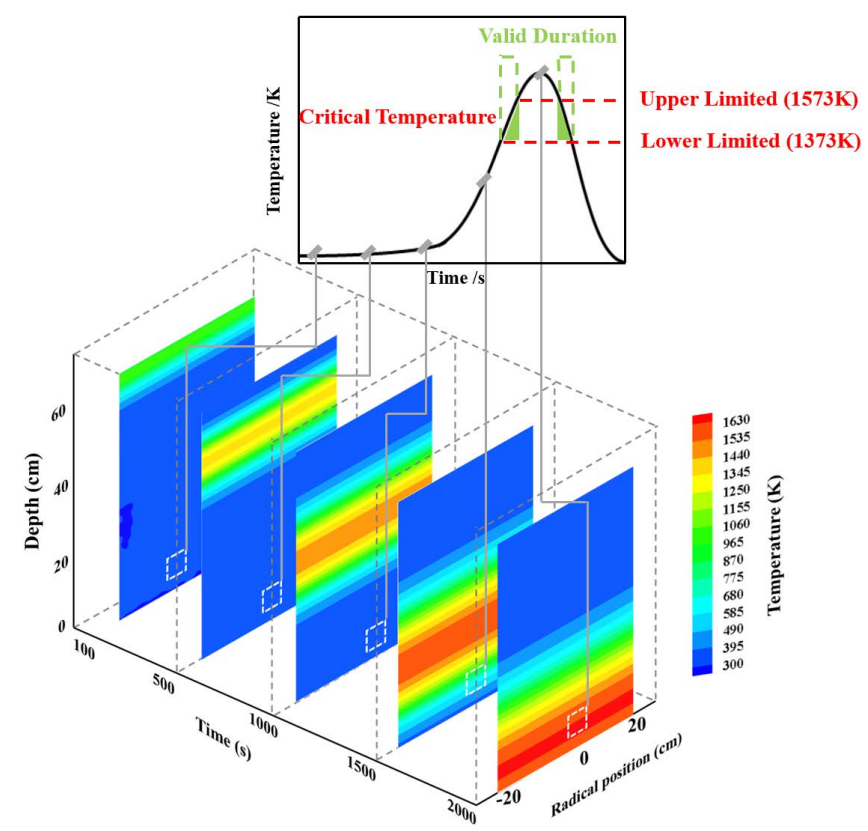

Fig. 3. The transient temperature profiles of the solid in the carbon combustion packed bed at different time nodes (inset: the transient temperature profile of the white dotted square against the time marked with the upper and lower limits of the critical temperatures and the valid duration). (Online version in color.)
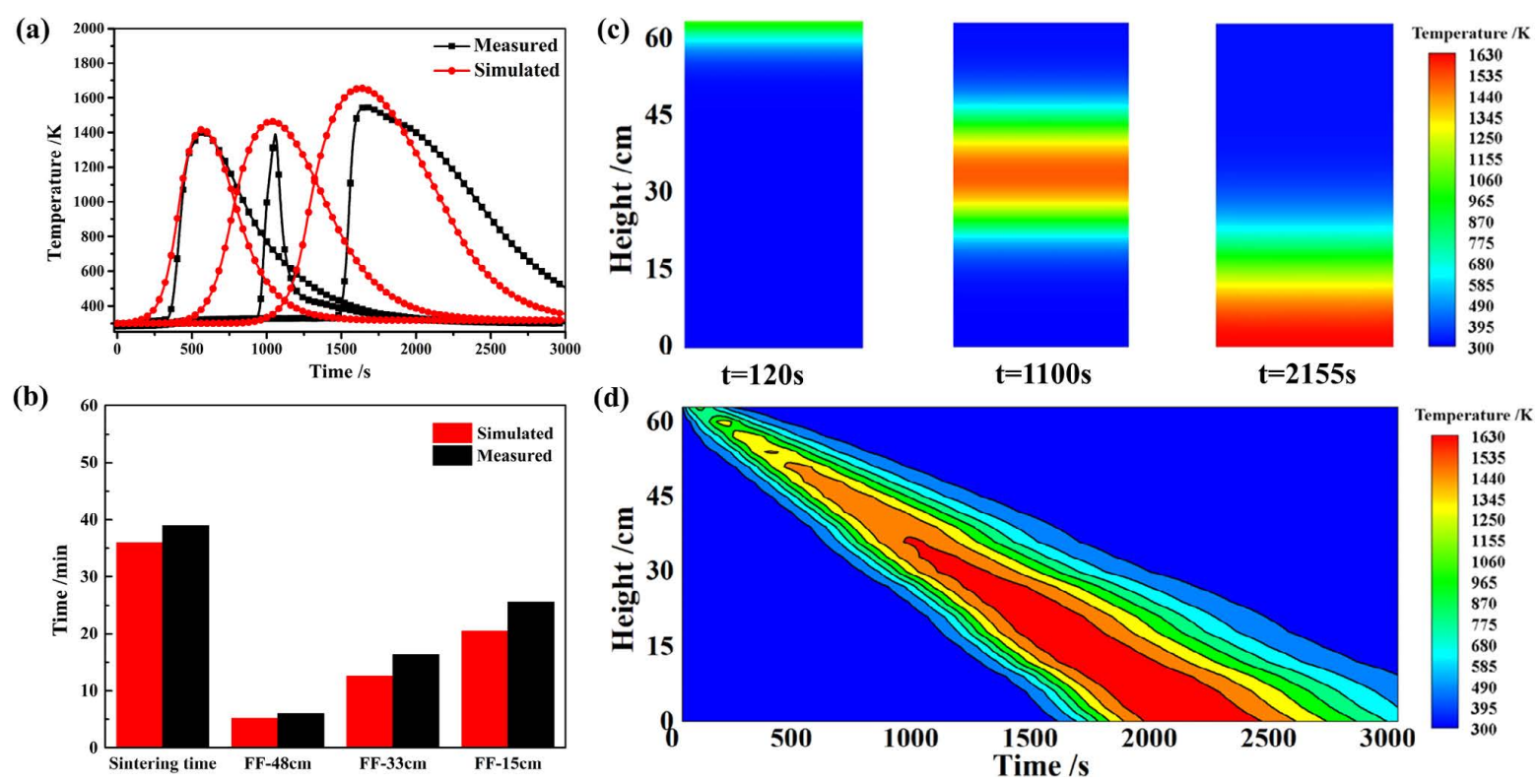

Fig. 2. (a) The comparison between the measured and simulated transient temperatures at $\mathrm{H}=15 \mathrm{~cm}, 33 \mathrm{~cm}$, and $48 \mathrm{~cm}$ measured from the bottom, (b) the comparisons of measured and simulated sintering time and the time when the flame front (FF) reaching different heights, (c) the snaps of the simulated solid temperature profiles at $120 \mathrm{~s}$, $1100 \mathrm{~s}$ and $2155 \mathrm{~s}$, and (d) the transient temperature distribution versus the increasing time in the packed bed. (Online version in color.) 


\section{Results and Discussion}

\subsection{Visualization Method of Quantifying Carbon Combustion Energy}

First of all, the cross-section of the sintering packed bed is divided into grids with the proper mesh size. Second, taking the white dotted square in the Fig. 3 as an example, the transient temperature is subjected to change at different time nodes as depicted in the inset. Third, based on the favorable conditions for liquid phase production, ${ }^{45,46)}$ the upper and lower limits of the critical temperature range are 1573 and $1373 \mathrm{~K}$, respectively, while the valid duration is between 180 and $300 \mathrm{~s}$. As a result, five visualization EI states, namely $\operatorname{EI}(0), \operatorname{EI}(+), \operatorname{EI}(++), \operatorname{EI}(-)$, and $\operatorname{EI}(--)$, are defined and explained in the Table 2.

The EI(0) state (marked in green) means the local temperature is between 1373 and $1573 \mathrm{~K}$ for $180-300 \mathrm{~s}$. In contrast, when the local temperature is higher than $1573 \mathrm{~K}$ or lower than $1373 \mathrm{~K}$, it is in the $\mathrm{EI}(++)$ state (marked in red) or in the EI(--) state (marked in grey blue). Besides, although the local temperature is between 1373 and 1573 $\mathrm{K}$, it is in the $\mathrm{EI}(+)$ state (marked in yellow) when its valid duration is longer than $300 \mathrm{~s}$, while it is in the EI(-) state (marked in dark blue) when shorter than 180 s. Overall, in

Table 2. Symbols, criterions and marked colors of the five energy input (EI) states. (Online version in color.)

\begin{tabular}{|c|c|c|c|c|c|}
\hline \multirow[b]{2}{*}{ symbol } & \multicolumn{2}{|c|}{ Insufficient energy input } & \multirow{2}{*}{$\frac{\text { Reasonable energy input }}{\operatorname{EI}(0)}$} & \multicolumn{2}{|c|}{ Excess energy input } \\
\hline & EI(--) & EI(-) & & $\mathrm{EI}(+)$ & $\mathrm{EI}(++)$ \\
\hline criterion & $\mathrm{T}<1373 \mathrm{~K}$ & $\begin{aligned} 1373 \mathrm{~K} & <\mathrm{T}<1573 \mathrm{~K} \\
\mathrm{t} & <180 \mathrm{~s}\end{aligned}$ & $\begin{array}{c}1373 \mathrm{~K} \leq \mathrm{T} \leq 1573 \mathrm{~K} \\
180 \mathrm{~s} \leq \mathrm{t} \leq 300 \mathrm{~s}\end{array}$ & $\begin{array}{c}1373 \mathrm{~K}<\mathrm{T}<1573 \mathrm{~K} \\
\mathrm{t}>300 \mathrm{~s}\end{array}$ & $\mathrm{~T}>1573 \mathrm{~K}$ \\
\hline marked color & & & & & \\
\hline
\end{tabular}

(a) Unit:cm

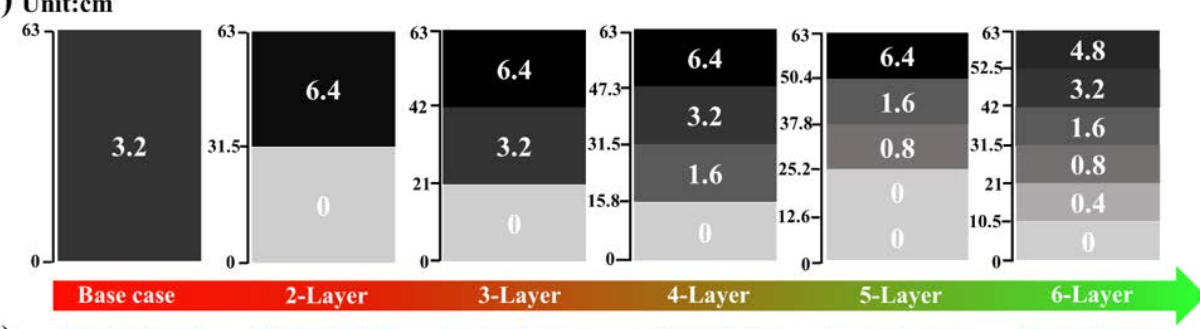

(b)
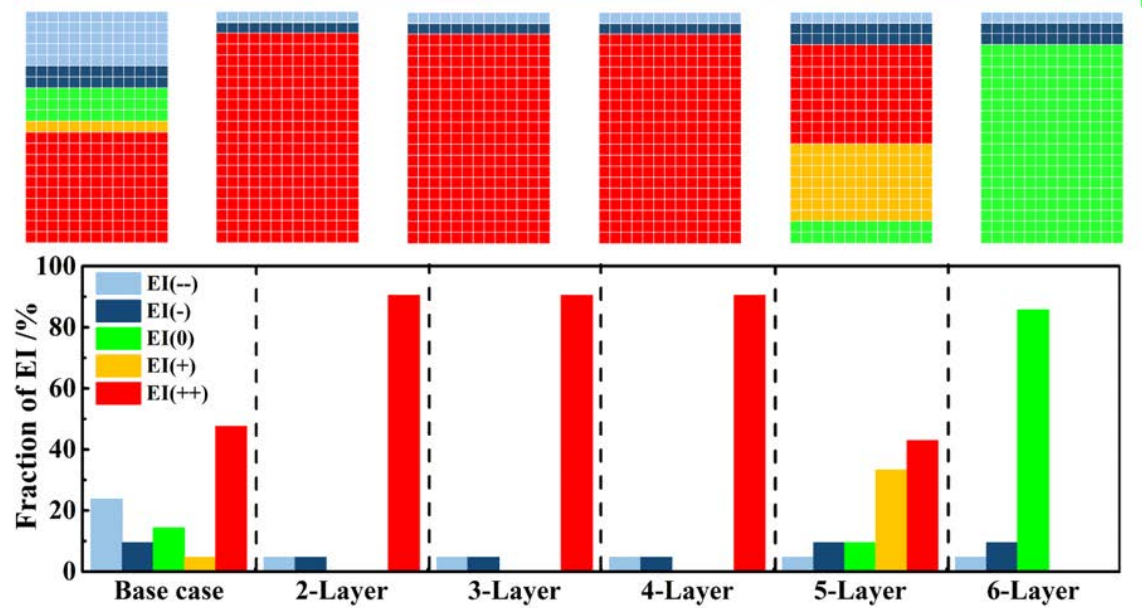

(c)

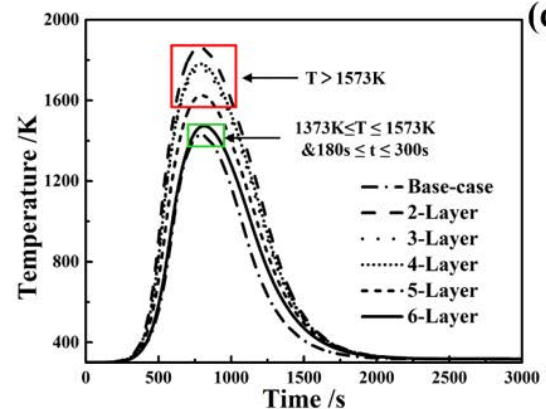

(d)

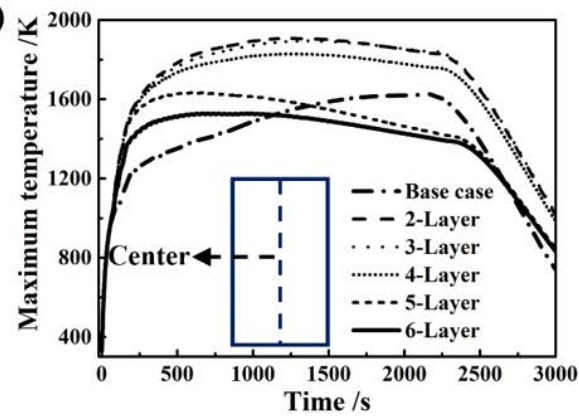

Fig. 4. Energy optimization through the carbon segregation in the 6 layer-structure packed beds: (a) the carbon concentration distributions (wt\%), (b) the predicted EI state distributions, (c) the transient temperature at $\mathrm{H}=42 \mathrm{~cm}$ and (d) the maximum central temperature distributions. (Online version in color.) 
contrast to the local regions in the $\operatorname{EI}(0)$ state, those in the EI(-) and EI(--) states require more energy input whereas that in the $\mathrm{EI}(+)$ and $\mathrm{EI}(++)$ states waste a considerable amount of energy. Therefore, the proposed method provides a quantitative and visual guidance to balance the energy input distribution in the sintering packed bed, thus expecting to achieve higher energy efficiency.

\subsection{Case Study I: Carbon Segregation in a Rectangu- lar Cross-section of Packed Bed}

This case study demonstrates how to use the aforementioned visualization method to compare and evaluate the effect of the carbon segregation on the energy efficiency in a rectangular cross-section of packed bed. The 6 packed beds in the Fig. 4(a) have 1, 2, 3, 4, 5 and 6-layer structures, respectively with different carbon concentrations. Then their cross-sections are discretized into $3 \times 3 \mathrm{~cm}$ square grids. Based on the transient temperature profile against the time extracted from the numerical results, each grid is judged and colorized as one of the previously defined EI states in the Fig. 4(b). Meanwhile, the transient temperature profiles at $\mathrm{H}=42 \mathrm{~cm}$, and maximum central temperature profiles are further compared in the Figs. 4(c)-4(d), respectively. To be more specific, in the base case, $3.2 \mathrm{wt} \%$ carbon is uniformly distributed in the packed bed. The results show that less than $15 \%$ of the cross section is in the $\operatorname{EI}(0)$ state. In contrast, more than $33 \%$ of the region in the upper part of the packed bed requires more energy input while approximately 50\% in the lower part wastes excess energy. These quantitative results indicate that carbon should be unevenly distributed to balance the energy distribution in the vertical direction of the packed bed. Therefore, another 5 cases are studied with 2- to 6-layer structure packed beds. Three points are worthy of note. First, although the average carbon concentrations in the base or 1,2 and 3-layer cases are the same, the latter two cases make better use of the heat storage effect, and approximately $90 \%$ of the region is in the $\mathrm{EI}(++)$ state, which provides great potential to reduce carbon consumption. Second, the 3 to 6-layer cases not only uniform the energy distribution, but also reduce the total carbon consumption by at most $43.8 \%$ under present numerical conditions. Because the maximum transient temperature in the packed bed is decreased significantly while it is still above the critical temperature.

\subsection{Case Study II: Cross-sectional Shape Optimization of Packed Bed with Uniform Carbon Distribution}

This second case demonstrates how to use the aforementioned visualization method to compare and evaluate the effect of the cross-sectional shape on the energy efficiency of the packed bed with uniform carbon distribution. The upper base length of the isosceles trapezoidal-shaped cross section (a)

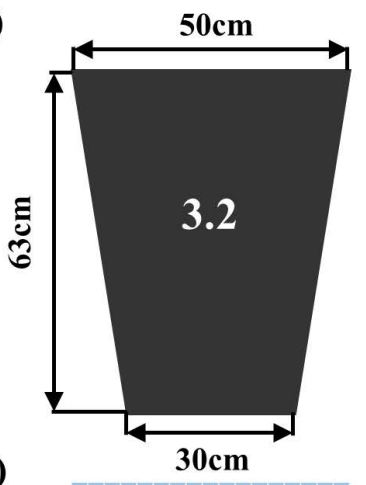

(b)

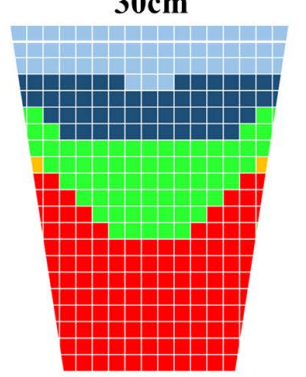

(c)

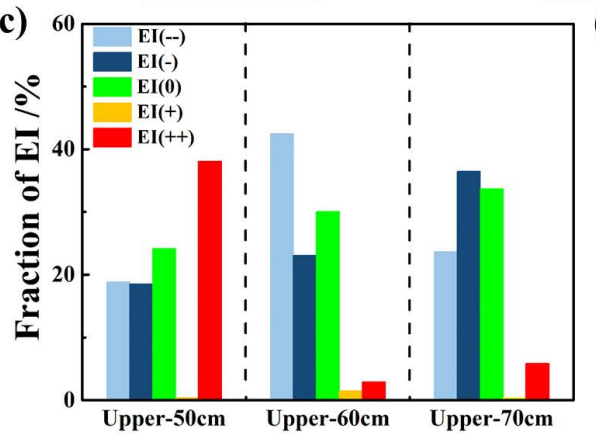

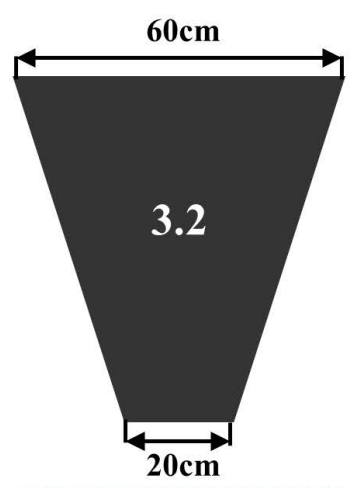

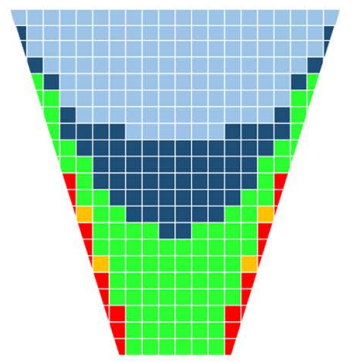

(d)

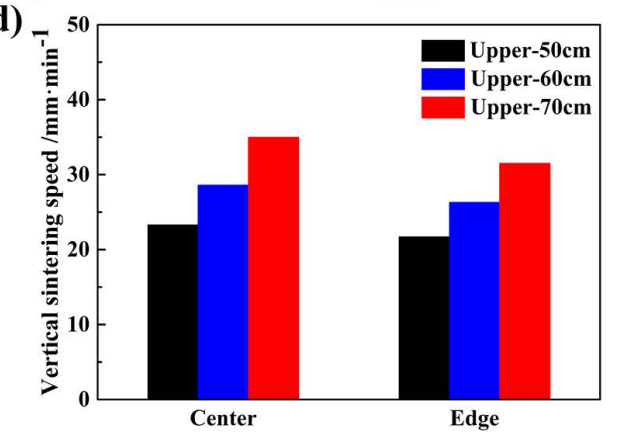

Fig. 5. Energy optimization through increasing upper base length of the trapezoidal cross sections of the packed beds: (a) the geometric dimensions, (b)(c) the predicted EI state distributions, and (d) the vertical sintering speed in the center and edge. (Online version in color.) 


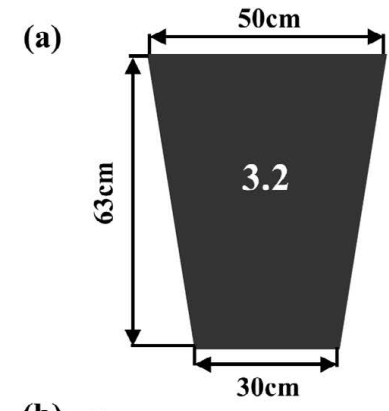

(b)
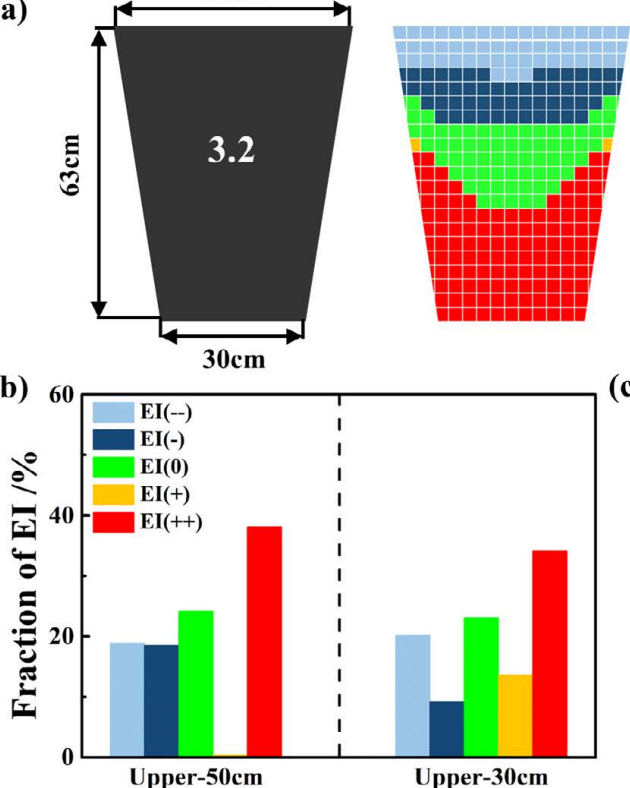

(c)

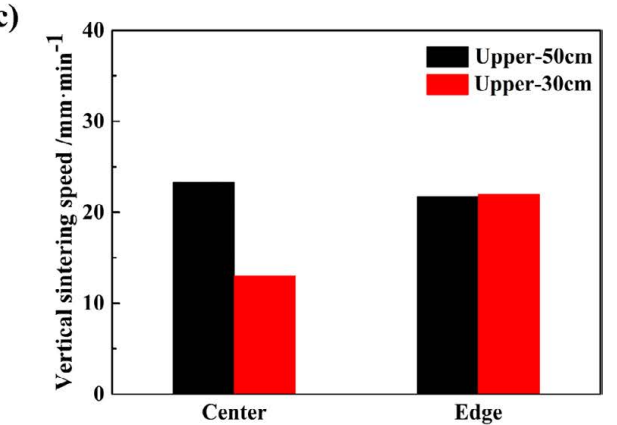

Fig. 6. (a) The geometric dimensions of the trapezoidal cross sections with $50 \mathrm{~cm}$ and $30 \mathrm{~cm}$ upper base, and the correspondingly predicted EI state distributions, (b) further comparison in terms of individual EI state, and (c) the vertical sintering speed in the center and edge. (Online version in color.)

of the packed bed in the Fig. 5(a) is increased from $50 \mathrm{~cm}$ to $60 \mathrm{~cm}$ and then to $70 \mathrm{~cm}$, while the lower base length is accordingly decreased from $30 \mathrm{~cm}$ to $20 \mathrm{~cm}$ and then to 10 $\mathrm{cm}$, respectively, while the cross-sectional area is constant. The EI state distributions are predicted and compared in the Figs. 5(b)-5(c). In addition to the V-shaped distributions, $24.2 \%, 30.0 \%$, and $33.7 \%$ of the region are in the $\mathrm{EI}(0)$ state while $37.4 \%, 65.6 \%$ and $60.1 \%$ are in the EI(-) or EI(--) state. The vertical sintering speeds in the center and edge are also compared in the Fig. 5(d). First of all, the vertical sintering speeds in the trapezoid-shaped cross-section of packed bed is higher than the counterpart in the base case (17.5 $\left.\mathrm{mm} \cdot \mathrm{min}^{-1}\right)$. The results indicate that the trapezoid-shaped cross-section with the long upper base length, in comparison to the rectangular one, can increase the sinter yield. Second, when the upper base length is increased from $40 \mathrm{~cm}$ to as long as $70 \mathrm{~cm}$, the vertical sintering speeds in the central and edge regions is respectively increased by at most $50.2 \%$ and $45.2 \%$, and an increasing unevenness of the vertical sintering speed between center and edge is noticed.

On the other hand, what if the trapezoidal cross section has a shorter upper base length? So the Fig. 6(a) introduces a new trapezoidal cross section with a $30 \mathrm{~cm}$ upper and a $50 \mathrm{~cm}$ lower base lengths, while the previous case with a $50 \mathrm{~cm}$ upper and a $30 \mathrm{~cm}$ lower base lengths is taken for comparison. The EI state distributions are predicted and compared in terms of individual states in the Fig. 6(b). The trapezoidal cross-section having shorter upper base length decreases the proportion of region in the EI(-) or EI(--) state from $37.4 \%$ to $29.3 \%$, while that in the $\mathrm{EI}(+)$ or $\mathrm{EI}(++)$ state increases from $38.5 \%$ to $47.6 \%$. However, the proportion in the $\operatorname{EI}(0)$ state is not significantly changed. When the upper base length is shorter than the lower base, the central temperature is higher than that near the edge. As a result, the EI state distribution changes from a V-shaped profile to a reversed $\mathrm{V}$-shaped one. Besides, the vertical sintering speeds in the central and edge regions are further compared in the Fig. 6(c). It is worth noting that the vertical sintering speed in the central region for the $30 \mathrm{~cm}$ upper base length case is less than half of the result for the $50 \mathrm{~cm}$ upper base length case. Besides, the uneven vertical sintering speed distribution between the center and edge regions in the former case greatly limits the yield. Overall, when the upper base length of the trapezoid-shaped cross-section of packed bed is decreased, the shortage of energy in the upper part can be relieved while the excess energy caused by the high central temperature in the lower part becomes the most prominent feature.

\section{Conclusions}

This work highlights a visualization method aiming to quantitatively evaluate the carbon combustion energy efficiency in the sintering packed bed. Its cross section is first discretized into $3 \times 3 \mathrm{~cm}$ square grids, and the transient temperature profile with respect to the time in each grid is extracted from the numerical results, after the established model is validated against the experimental measurements. The five EI states are defined according to the criteria consisting of the critical temperature range and its duration. At last, two case studies, namely the effects of carbon segregation and cross-sectional shape on the energy efficiency of packed bed, are demonstrated to fully understand the definition, process, application of the visualization method, and to stimulate the application potential in other fields.

\section{Acknowledgments}

The authors gratefully acknowledge the critical comments from anonymous editors and reviewers, and funding through projects from the Fundamental Research Funds for the Central Universities (2020CDJQY-A005) and the Natural Science Foundation of Chongqing, China (cstc2019jcyjmsxmX0089). 


\section{Nomenclature}

$A_{C}:$ volumetric surface area of carbon particle $\left(\mathrm{m}^{2} / \mathrm{m}^{3}\right)$

$A_{S}$ : specific surface area of convective heat transfer $\left(\mathrm{m}^{2} / \mathrm{m}^{3}\right)$

$C_{c o}:$ CO mole concentration $\left(\mathrm{mol} / \mathrm{m}^{3}\right)$

$C_{h_{2} O}: \mathrm{H}_{2} \mathrm{O}$ mole concentration $\left(\mathrm{mol} / \mathrm{m}^{3}\right)$

$C_{\mathrm{O}_{2}}: \mathrm{O}_{2}$ mole concentration $\left(\mathrm{mol} / \mathrm{m}^{3}\right)$

$C_{p}$ : solid specific heat $(\mathrm{J} /(\mathrm{kg} \cdot \mathrm{K}))$

$c_{n}$ : carbon concentration in the nth layer $(\mathrm{wt} \%)$

$F_{V}$ : gas flow resistance $(\mathrm{Pa} \cdot \mathrm{m})$

$h_{\text {conv }}$ : convection heat transfer coefficient $\mathrm{W} /\left(\mathrm{m}^{2} \cdot \mathrm{K}\right)$

$h_{s}$ : solid enthalpy $(\mathrm{kJ} / \mathrm{mol})$

$k_{c}$ : reaction rate constant $(\mathrm{m} / \mathrm{s})$

$k_{\text {coating: }}$ mass transfer coefficient of ash layer $(\mathrm{m} / \mathrm{s})$

$k_{\text {film }}$ : film mass transfer coefficient $(\mathrm{m} / \mathrm{s})$

$k_{s, e f f:}$ solid effective coefficient $(\mathrm{W} /(\mathrm{m} \cdot \mathrm{K}))$

$\dot{m}_{k}$ : mass production rate $\left(\mathrm{kg} /\left(\mathrm{m}^{3} \cdot \mathrm{s}\right)\right)$

$P$ : $\operatorname{pressure}(\mathrm{Pa})$

$q_{g, k}$ : volumetric heat source of gas $\left(\mathrm{J} /\left(\mathrm{m}^{3} \cdot \mathrm{s}\right)\right)$

$q_{s, k}$ : volumetric heat source of solid $\left(\mathrm{J} /\left(\mathrm{m}^{3} \cdot \mathrm{s}\right)\right)$

$R_{\text {carbon }}$ : reaction rate of carbon $\left(\mathrm{kg} / \mathrm{s} / \mathrm{m}^{3}\right)$

$R_{c o}$ : reaction rate of $\mathrm{CO}\left(\mathrm{kg} / \mathrm{s} / \mathrm{m}^{3}\right)$

$r_{0}$ : initial particle radius $(\mathrm{m})$

$r_{\text {carbon: }}$ transient carbon radius $(\mathrm{m})$

$T$ : temperature $(\mathrm{K})$

$W_{C}$ : carbon molecular weight $(\mathrm{kg} / \mathrm{mol})$

$Y$ : mass fraction (-)

$y$ : coordinate value in $\mathrm{y}$-axis $(\mathrm{m})$

Greek alphabets

$\varepsilon$ : packed bed porosity (-)

$u$ : velocity $(\mathrm{m} / \mathrm{s})$

$\mu$ : viscosity $(\mathrm{Pa} \cdot \mathrm{s})$

$\xi$ : a factor of particle area (-)

$\rho$ : density $\left(\mathrm{kg} / \mathrm{m}^{3}\right)$

Subscripts

g: gas

$s$ : solid

0 : initial state

i: transient state

\section{REFERENCES}

1) F. Yi, H. K. Zou, G. W. Chu, L. Shao and J. F. Chen: Chem. Eng J., 145 (2009), 377. https://doi.org/10.1016/j.cej.2008.08.004

2) A. Mondal, A. Pramanik, A. Bhowal and S. Datta: Chem. Eng. Res Des., 90 (2012), 453. https://doi.org/10.1016/j.cherd.2011.08.008

3) N. Qureshi and H. P. Blaschek: Renew. Energy, 22 (2001), 557. https://doi.org/10.1016/S0960-1481(00)00108-7

4) S. Hama, A. Yoshida, N. Tamadani, H. Noda and A. Kondo: Bioresour. Technol., 135 (2013), 417. https://doi.org/10.1016/j. biortech.2012.06.059

5) Y. B. Yang, C. K. Ryu, A. Khor, V. N. Sharifi and J. Swithenbank: Fuel, 84 (2005), 2026. https://doi.org/10.1016/i.fuel.2005.04.022

6) H. Zhou, M. X. Zhou, Z. H. Liu, M. Cheng and J. Z. Chen: Fuel, 179 (2016), 322. https://doi.org/10.1016/j.fuel.2016.03.098

7) H. Zhou, M. X. Zhou, Z. H. Liu, M. Cheng, C. Z. Qiu and K. F. Cen ISIJ Int., 55 (2015), 2556. https://doi.org/10.2355/isijinternational. ISIJINT-2015-311

8) Y. Yu, B. K. Li, C. J. Wang, Z. Z. Fang, X. Yang and F. Tsukihashi: Energy, 179 (2019), 792. https://doi.org/10.1016/j.energy.2019.05.06

9) Z. L. Cheng, J. Yang, L. Zhou, Y. Liu and Q. W. Wang: Appl. Energy, 161 (2016), 364. https://doi.org/10.1016/j.apenergy.2015.09.095

10) K. Taira: Fuel, 272 (2020), 117735. https://doi.org/10.1016/j. fuel.2020.117735

11) E. Kasai, S. Komarov, K. Nushiro and M. Nakano: ISIJ Int., 45 (2005), 538. https://doi.org/10.2355/isijinternational.45.538

12) O. Ishiyama, K. Hara, M. Matsumura, K. Higuchi and S. Nomura:
Tetsu-to-Hagané, 103 (2017), 564 (in Japanese). https://doi. org/10.2355/tetsutohagane.TETSU-2017-007

13) J. A. de Castro, J. L. Pereira, V. S. Guilherme, E. P. da Rocha and A. B. França: J. Mater. Res. Technol., 2 (2013), 323. https://doi. org/10.1016/j.jmrt.2013.06.002

14) C. Lanzerstorfer, B. Bamberger-strassmayr and K. Pilz: ISIJ Int., 55 (2015), 758. https://doi.org/10.2355/isijinternational.55.758

15) Y. Kang, C. Liu, Y. Z. Zhang, H. W. Xing and K. Zhao: ISIJ Int., 60 (2020), 1633. https://doi.org/10.2355/isijinternational. ISIJINT-2019-505

16) C. E. Loo and J. Heikkinen: ISIJ Int., 52 (2012), 2158. https://doi. org/10.2355/isijinternational.52.2158

17) M. Fernández, I. Mediavilla, R. Barro, E. Borjabad, R. Ramos and J. E. Carrasco: Fuel, 239 (2019), 1115. https://doi.org/10.1016/j. fuel.2018.11.115

18) E. Kasai, B. Batcaihan, Y. Omori, N. Sakamoto and A. Kumasaka: ISIJ Int., 31 (1991), 1286. https://doi.org/10.2355/isijinternational.31.1286

19) Z. Ma, R. Xiao and L. Y. Chen: Fuel Process. Technol., 168 (2017), 20. https://doi.org/10.1016/j.fuproc.2017.08.029

20) T. C. Ooi, D. Thompson, D. R. Anderson, R. Fisher, T. Fray and M. Zandi: Combust. Flame, 158 (2011), 979. https://doi.org/10.1016/j. combustflame.2011.01.020

21) W. Yang, S. M. Choi, E. S. Choi, D. W. Ri and S. Kim: Combust. Flame, 145 (2006), 447. https://doi.org/10.1016/j.combustflame. 2006.01.005

22) Z. L. Cheng, J. Yang, L. Zhou, W. X. Li, Y. Liu and Q. W. Wang: Chem. Eng. Trans., 45 (2015), 877. https://doi.org/10.3303/ CET1545147

23) H. Zhou, Z. H. Liu, M. Cheng, M. X. Zhou and R. P. Liu: Energy Fuels, 29 (2015), 974. https://doi.org/10.1021/ef502524y

24) B. Zhang, J. M. Zhou and M. Li: Appl. Therm. Eng., 131 (2018), 70. https://doi.org/10.1016/j.applthermaleng.2017.11.148

25) Y. G. Chen, Z. C. Guo and Z. Wang: Fuel Process. Technol., 90 (2009), 933. https://doi.org/10.1016/j.fuproc.2009.03.021

26) J. Hu, M. Wu, X. Chen, S. Du, P. Zhang, W. H. Cao and J. H. She: IEEE Trans. Ind. Electron., 65 (2018), 8778. https://doi.org/10.1109/ TIE.2018.2811371

27) K. Taira: Fuel, 236 (2019), 244. https://doi.org/10.1016/j. fuel.2018.09.008

28) W. Yang, C. K. Ryu, S. Choi, E. Choi, D. Lee and W. Huh: ISIJ Int., 44 (2004), 492. https://doi.org/10.2355/isijinternational.44.492

29) J. P. Zhao, C. E. Loo, J. L. Yuan, F. Wang, J. T. Wang, H. C. Zhang and H. Miao: Energy Fuels, 32 (2018), 8743. https://doi.org/10.1021/ acs.energyfuels. 8 b00939

30) S. Machida, T. Higuchi, N. Oyama, H. Sato, K. Takeda, K. Yamashita and K. Tamura: ISIJ Int., 49 (2009), 667. https://doi. org/10.2355/isijinternational.49.667

31) J. P. Zhao, C. E. Loo and B. G. Ellis: ISIJ Int., 56 (2016), 1148. https://doi.org/10.2355/isijinternational.ISIJINT-2015-686

32) W. Yang, C. Ryu, S. Choi, E. Choi, D. Lee and W. Huh: ISIJ Int., 44 (2004), 492. https://doi.org/10.2355/isijinternational.44.492

33) W. Yang, C. Ryu, S. Choi, E. Choi, D. W. Ri and W. Huh: Met. Mater. Int., 10 (2004), 493. https://doi.org/10.1007/BF03027355

34) J. A. de Castro, L. M. da Silva, G. A. de Medeiros, E. M. de Oliveira and H. Nogami: J. Mater. Res. Technol., 9 (2020), 6001. https://doi. org/10.1016/j.jmrt.2020.04.004

35) K. I. Ohno, K. Noda, K. Nishioka, T. Maeda and M. Shimizu: Tetsuto-Hagané, 101 (2015), 19 (in Japanese). https://doi.org/10.2355/ tetsutohagane.101.19

36) M. L. Hobbs, P. T. Radulovic and L. D. Smoot: Prog. Energy Combust. Sci., 19 (1993), 505. https://doi.org/10.1016/0360-1285(93)90003-W

37) A. Jensen, J. E. Johnsson, J. Andries, K. Laughlin, G. Read, M. Mayer, H. Baumann and B. Bonn: Fuel, 74 (1995), 1555. https://doi. org/10.1016/0016-2361(95)00155-X

38) G. Wang, Z. Wen, G. F. Lou, R. F. Dou, X. W. Li, X. L. Liu and F. Y. Su: Int. J. Heat Mass Transf., 97 (2016), 964. https://doi. org/10.1016/j.ijheatmasstransfer.2016.02.08

39) S. Chapela, J. Porteiro, M. A. Gmez, D. Patio and J. L. Mguez: Fuel, 234 (2018), 1099. https://doi.org/10.1016/j.fuel.2018.07.121

40) M. Huang, S. Gowdagiri, X. M. Cesari and M. A. Oehlschlaeger: Fuel, 181 (2016), 170. https://doi.org/10.1016/j.fuel.2016.04.137

41) Z. Zheng, W. Yang, P. Yu, Y. Cai, H. Zhou, S. K. Boon and P. Subbaiah: Fuel, 259 (2020), 116083. https://doi.org/10.1016/j. fuel.2019.116083

42) X. H. Fan, Z. Y. Yu, M. Gan, X. L. Chen, T. Jiang and H. L. Wen: ISIJ Int., 54 (2014), 2541. https://doi.org/10.2355/isijinternational.54.2541

43) S. Zhang, Z. Wen, G. Wang, R. Dou, X. Liu and X. Li: Ironmaking Steelmaking, 47 (2020), 368. https://doi.org/10.1080/03019233.2018. 1521565

44) H. Zhou, J. P. Zhao, C. E. Loo, B. G. Ellis and K. F. Cen: ISIJ Int., 52 (2012), 1550. https://doi.org/10.2355/isijinternational.52.1550

45) E. Kasai, Y. Sakano, T. Kawaguchi and T. Nakamura: ISIJ Int., 40 (2000), 857. https://doi.org/10.2355/isijinternational.40.857

46) G. L. Zhang, S. L. Wu, S. G. Chen, J. Zhu, J. X. Fan and B. Su: ISIJ Int., 53 (2013), 1515. https://doi.org/10.2355/isijinternational.53.1515 